\title{
Paradoxical approach to the management of faecal incontinence in normal children
}

\author{
B Knights, S K Pandey
}

\begin{abstract}
Three children with faecal incontinence, in whom conventional treatment had failed, were managed with a regimen that focuses on the symptoms and present behaviour. It is short term and uses a paradoxical approach.
\end{abstract}

Faecal incontinence is a common but intractable problem affecting about $1 \cdot 5 \%$ of $7-8$ year olds. ${ }^{1}$ Secrecy often surrounds the problem in the family; it is generally not discussed with others even at the cost of disheartening consequencesfor example, family distress, failure at school, social isolation, and power struggles within the family. ${ }^{2}$ Soiled pants are sometimes concealed in unexpected places, adding to the distress of the family. This distress is often intensified by the child's apparent lack of concern for his behaviour even to the point of 'not caring'. The patient usually denies that anything untoward happens, while parents are trying everything within their grasp to help him.

Some may argue that it is probably the parents who are suffering most from their child's faecal incontinence. A vicious circle is set up with a steady deterioration in the relationships within the family and the consequent perpetuation of the problem. In the end a power struggle ensues, with all the interventions maintaining faecal incontinence despite everyone's best intentions.

The persistence of the behaviour is explained by the continuing reinforcements in the child's system of social interaction, ${ }^{3}$ particularly the family, but also school, extended family, and professionals with whom he associates. The behaviour of the child encourages the adoption of 'solution' behaviour to try and change the child's behaviour. The failure of the 'solution' behaviour results in more of the same because there appears to be no alternative to trying to get him to go to the toilet, by talking, persuasion, sitting on the toilet, and so on. The professional becomes part of that 'maintaining' system by doing much the same, resulting in a failure of normal bowel habits.

Various treatments-for example, medical, behavioural, ${ }^{4-5}$ family, ${ }^{6}$ psychoanalytic, dietary, ${ }^{8}$ surgical, ${ }^{9}$ electrostimulation, ${ }^{10}$ and combined ${ }^{11}$-have been tried with varying success. Nevertheless no single satisfactory treatment has been described. Evaluations of various methods are made more difficult because of the spontaneous improvement of the condition with age. In addition, some of the reported therapeutic regimens are costly and time consuming, and would seriously tax the resources of a district general hospital.

We describe a paradoxical approach to this problem, which may help the patient with more resistant symptoms and which should be considered when conventional methods seem to be ineffective. This method is based on the principle that a person is expected to change by using the symptom itself as an effective prescription, and is based on the work of the Mental Research Institute Group and the systemic view of problem formation and resolution. ${ }^{12}$

\section{Patients and methods}

At the first outpatient visit, which lasts for about half an hour, parents and patient are interviewed. A detailed history is taken, concentrating on information about frequency, duration, where faeces are deposited, other behaviour difficulties, and family and school problems. The history will indicate the likelihood of organic problems and the need for any investigations.

Most families presenting with a child who is soiling regularly will have 'tried everything' and think that he 'doesn't seem to care', and that 'nothing works'. These parents are strongly motivated to try anything that may help change what is beginning to seem an intractable problem.

It is important to talk with the child away from the parents at some stage, the interviewer showing an intense interest in the child by seeking physical closeness, talking softly, and generally being friendly. A power struggle between the child and the doctor may develop when the problem of soiling is shifted to the context of relationships as the interview progresses.

Before embarking on the paradoxical approach it is discussed with the parents, and is only carried out with their agreement. Most parents are keen to try anything that might work.

\section{PARADOXICAL APPROACHES}

The aim of the paradoxical approach is to make the child think about the effect he is having on others, and to make him think about his bowel actions in a way he has not done before. He is encouraged to continue his soiling because that is 'how you express your feelings'. The doctor may use any of the following approaches, depending upon various factors-for example, 
the age and cognitive level of the child, the experience of the doctor, and the sophistication of parents.

(1) 'Have you heard about Poohland? Do you know children in "Poohland" do not use a toilet? In Poohland people "Pooh" anywhere they want and as many times as they wish. We are looking for a king/queen and you would do nicely for that position.' It is important to monitor the feedback from the child and alter the intervention accordingly.

(2) 'Do you love your mum? I just wonder how you say you love your mum but you do the most horrible things to her. Is that how you treat your friends? I think you do it, because you don't like her.' This surprises and at times shocks the child.

(3) 'I like children who "pooh" in their pants. it is OK for you because that is the way you show your feelings, some people get upset but you fill your pants. I would like you to continue and in fact to do it some more!'

These approaches are a novelty to parents, which may add some element of humour. Parents should be made to perceive the doctor as someone in whom they can believe and who is ready to see the problem through to its end. They almost all find the method acceptable and usually grasp the ideas quickly.

If the child soils at home parents are advised to remind him how much the doctor will be pleased to hear about it. The subsequent sessions reinforce the message and may be modified according to the response. The pleasure that the doctor feels if soiling has improved, should be concealed beneath a response of disappointment.

\section{Case reports}

This method has been successfully used at the Bethel Hospital, Norwich for the last few years and in this paper we report on three of our recent cases.

\section{CASE 1}

An 11 year old boy was referred by his general practitioner with a history of faecal incontinence for the past six years. He was toilet trained at the age of 2.5 years and everything was fine when he started school at the age of 4 . There were no problems until he was 5.5 years old, when faecal incontinence started. At school everything was fine and this was confirmed by his class teacher and his parents. His general practitioner had diagnosed faecal incontinence secondary to severe constipation, and he was given laxatives and enemas with temporary improvement. He had seen a dietitian and was on a high fibre diet. His health visitor had tried behaviour modification methods (for example, star charts), with no success. His longest period of continence was two weeks.

After assessment in the outpatient department it was decided to treat him with the paradoxical approach 'Poohland'. His soiling stopped a day after he was seen. He was followed up twice at two weekly intervals and, as all was well, he was discharged. At the time of writing (10 months since first seen) everything was fine.

\section{CASE 2}

A 13 year old boy was referred by a paediatric consultant with a history of faecal incontinence for the last nine years. He was toilet trained at the age of 2 years, but continued to soil his pants once every two or three days.

At the age of 4 years he was soiling three or four times a day, although he never soiled at school. At the age of 8 years he started soiling at school and was using a dozen pairs of pants a week at the time of the interview. Conventional methods of management had failed. He had been admitted to hospital once when he was 12 years old to be 'cleaned out', but he refused enemas.

At the first interview he was noted to be shy and did not make eye contact. After discussion with his parents it was decided to try him with a paradoxical approach. By his follow up visit after two weeks he had only soiled three times. He was reviewed again twice (at monthly intervals) and, as he was consistently clean, he was discharged from the clinic. It is more than six months since his discharge at the time of writing, and he had had no further faecal incontinence.

\section{CASE 3}

A 5 year old girl who had been soiling continuously and was not responding to conventional treatment was referred by a consultant paediatrician. She came from a middle class family who had no obvious problems.

Her mother was, of course, distraught about this apparently deliberate soiling, and both the child's parents and her teacher described her as a stubborn child. The intervention related her behaviour to her relationship with her mother. The apparent paradox of loving her mother but at the same time being horrible to her was pointed out and possible solutions to this dilemma were offered. She was angry with the doctor, and opted to stop soiling after the second session. A short relapse was followed by her becoming clean permanently.

\section{Discussion}

Non-organic faecal incontinence can be divided into two types: type 1 is incontinence with retention in which there is a large faecal mass in the rectum with faecal leakage around it, which usually causes frequent soiled pants; and type 2 is incontinence without retention, in which the rectum is empty and faeces are deposited in places other than the toilet.

Paradoxical psychotherapy is a useful, effective, and relatively new treatment. The aim of this report is to highlight paradoxical treatment of faecal incontinehce as an efficient and cost effective treatment when conventional methods have failed.

These methods are probably more appropriate for the type 2 soiling behaviour, and regardless of how appropriate a case might be for para- 
doxical treatment the doctor must be able to think paradoxically. He must therefore see the symptom as a vehicle of change, see the symptom in functionally positive terms-for example, as a sign of caring, protection, and closeness, and must understand how the family and professionals are reacting.

Paradoxical treatment seems to be most efficient and effective when the child has resisted any changes in the past. The use of these methods with an easy and cooperative case may be no more effective than other techniques. ${ }^{13}$ The methods are undoubtedly effective in reducing the soiling quickly, but it is always difficult to measure the true effectiveness of any treatment in a self limiting condition.

There is, however, no doubt in our mind that relationships in the family improve rapidly as the child shows his mother and the doctor that he really does love her and does not want to live in 'Poohland'. The theory is simple to understand but at times difficult to execute. The doctor must, as in all work with children, be comfortable with the style of work or it is likely to fail.

We have outlined a method that can be quickly effective in producing a change in children who continue soiling despite all other efforts. This is a technique that some may find interesting and challenging and its future lies in improving the selective criteria more scientifically and at the same time refining the interventions.

We thank Dr R Beach for his comments and Mrs D Lockwood for typing the manuscript.

1 Schaefter CE. Childhood encopresis: its causes and therapy. New York: Van Nostrand Teinhold, 1979.

2 Levine MD. Encopresis: its potentiation, evaluation and alleviation. Pediatr Clin North Am 1982;29:315-30.

3 Watzlawick P, Weakland JH. The interactional studies at Matzlawick P, Weakland JH. The interactional studies at
Mental Research Institute 1965-1974. New York: WW Mental Research

4 Neale DH. Behaviour therapy and encopresis in children. Behav Res Ther 1963;1:139-49.

5 Lowery SP, Srour JW, Whitehead WE, Marvin NM. Habit training as treatment of encopresis secondary to chronic constipation. F Pediatr Gastroenterol Nutr 1985;4:397-40

6 Lask B. Family therapy. Arch Dis Child 1985;60:297-8.

7 Pinkerton P. Psychogenic megacolon in children: the implications of bowel negativism. Arch Dis Child 1958;33: 372-80.

8 Berg I. Constipation and soiling in childhood. $\mathrm{Br} \mathrm{Med} \mathrm{F}$ 1976;i:900

9 Poirson J, Ghislain D. Severe chronic constipation as a surgical problem. Surg Clin North Am 1983;63:193-217.

10 Avaliani LV, Gachechiladze TV. Lechenie enkopreza U deteiputem elektrosti-muliatsii priamoi kishki. Vestn Khir 1983;131:108-10.

11 Wakefield MA, Woodbridge C, Steward J, Croke WM. A treatment programme for faecal incontinence. Dev Med treatment programme for faeca

12 Watzlawick P, Weakland JH, Fisch R. Change: principles of problem formation and problem resolutions. New York: WW Norton, 1974.

13 Weeks GR, L'Abate L. Paradoxical psychotherapy: theory and practice with individuals, couples and families. New York: Brunner/Hazel, 1982

\section{Commentary}

Paradoxical techniques have been around long before psychiatrists and allied workers discovered them for therapeutic purposes. We have always known that under certain circumstances people are inclined to do quite the reverse of what we want them to do. We might then deliberately instruct them to do the opposite in the hope that they will resist this injunction as well and thereby behave in the way which we desire: surely, parents of adolescent children are more than familiar with that strategy.

Clinicians have used paradoxical methods for many decades, ${ }^{1}$ but their arrival in the field of family therapy is fairly recent. ${ }^{2} 3$ In Europe the work of the Milan team has been particularly influential. ${ }^{4}$ Their treatment sessions of anorectic and psychotic patients and their families culminated in the whole family being 'paradoxed' with a prescription telling them to continue with the symptom and related behaviours because it benefited the whole family. The patient's symptoms were viewed as a (failed) solution to problems involving the whole family. The patient's efforts to resolve the family problem were therefore positively connoted as this apparently being the only thing that he or she could do in the service of the family'. This 'sacrifice intervention' often resulted in the symptoms vanishing, but families frequently vanished from the treatment too. ${ }^{5}$ Some parents subsequently complained that they had been told by experts that self starvation or hearing voices were a 'good thing' and that their offspring had been encouraged to remain ill or even get worse. This not infrequently led to considerable acrimony between referring doctors and paradoxical therapists. The latter thus had to modify their approach and make a shift away from implying that a family 'needed' a symptom. Nowadays symptoms are seen as something that people have got used to, habits which are hard to break. In this way it has been possible to avoid seeming to approve of some terrible symptom.

What then is paradoxical about such an approach? If a patient wants to be cured of a symptom but appears to resist any therapeutic efforts, he can be released from this apparently paradoxical situation by means of a 'counterparadox'. The patient is thus put in a bind: he can only resist treatment by giving up the symptom, or else he can only maintain the symptom by giving up the resistance. With treatment resistant patients or families this intervention creates a bind: the patient can only 'win' (or defeat the doctor) by not following the prescription of 'no change': he therefore has to relinquish the symptomatic behaviour. If, however, he follows the prescription of doing more of the same, the patient accepts what the doctor is asking him to do, namely to produce his problems deliberately. Learning to produce the symptomatic behaviour at will can teach one a lot about how to prevent it at will. It is therefore a first step to attaining control over a problem.

There are other paradoxical techniques apart from symptom prescription. ${ }^{6}$ By using restraining strategies the therapist apparently attempts to slow down the patient's efforts to overcome his problems. Therapists can do this by discouraging or even denying the possibility of change, so that sometimes the patient may get better to prove him wrong.

Other paradoxical methods include positioning techniques, which are at times used by apparently accepting and exaggerating the 